\title{
Surgical Management of Sacral Chordomas: Illustrative Cases and Current Management Paradigms
}

Arjun V. Pendharkar ${ }^{1}$, Allen L. Ho ${ }^{1}$, Eric S. Sussman ${ }^{2}$, Atman Desai STANFORD UNIVERSITY 3

1. Neurosurgery, Stanford University School of Medicine, Stanford, USA 2. Department of Neurosurgery, Stanford University School of Medicine 3. Department of Neurosurgery, Stanford University School of Medicine, Stanford, USA

$\square$ Corresponding author: Arjun V. Pendharkar, apendhar@stanford.edu Disclosures can be found in Additional Information at the end of the article

\section{Abstract}

Sacral chordomas represent more than $50 \%$ of all sacral tumors. These slow-growing, malignant lesions present insidiously and are often large and intimately involved with sacral neurovascular and pelvic structures. En bloc resection is the only well-established predictor of progression-free survival. Optimal surgical management requires a complex multi-disciplinary approach. Here, we describe two cases of sacral chordoma and review current management paradigms.

Categories: Radiation Oncology, Neurosurgery, Oncology

Keywords: sacral chordoma

\section{Introduction}

Chordomas are slow-growing malignant neoplasms that represent approximately $1-4 \%$ of all primary bone tumors [1]. Epidemiological studies report an incidence of 0.08 per 100,000. There is a predominance for the male gender and presentation in the $5^{\text {th }}$ and $6^{\text {th }}$ decade. Median survival is estimated to be 6.29 years. Five, 10 and 20 year survivals are approximately $68 \%$, $40 \%$, and $13 \%$, respectively [2].

Received 07/12/2015

Review began $07 / 25 / 2015$ Review ended 07/30/2015 Published 08/12/2015

(C) Copyright 2015

Pendharkar et al. This is an open access article distributed under the terms of the Creative Commons Attribution License CC-BY 3.0., which permits unrestricted use, distribution, and reproduction in any medium, provided the original author and source are credited.
These tumors almost always arise in the midline axial skeleton suggesting an embryological origin from vestigial elements of the notochord [1]. Recent epidemiological studies report approximately an equal distribution between the skull base, mobile spine, and sacrum; however, chordomas represent greater than $50 \%$ of all tumors of the sacrum. Due to their relatively slow growth rate, sacral chordomas often remain clinically silent until the lesions reach a large size. When symptomatic, these tumors commonly present with non-specific and progressive deep pain and/or radiculopathy [3].

Radiological workup usually reveals a destructive bone lesion involving the vertebral body on CT, with a corresponding soft tissue mass on MRI that is T2 hyperintense and heterogeneously contrast-enhancing. There is often local invasion into the adjacent disc spaces. From a pathological perspective, chordomas are considered low to intermediate grade lesions. Due to extensive disease progression at the time of presentation and the high rate of local recurrence, these lesions are considered malignant and require multi-disciplinary management. 
Here, we report two recent cases of sacral chordoma treated with en bloc resection and stereotactic radiosurgery and review current management paradigms for this challenging clinical entity.

\section{Case Presentation}

Informed patient consent was obtained for all participants in this report. No identifying patient information was included,

\section{Patient 1}

The patient is a 34-year-old previously healthy male who presented with three years of progressive sacrococcygeal pain, worse with sitting. He denied lower extremity weakness or sensory changes and did not have any bowel or bladder incontinence. On examination, he had no neurological deficits and had tenderness to palpation over the distal sacrum and coccyx. MRI revealed a T2 intense well-circumscribed sacrococcygeal mass approximately $3 \times 2 \times 2 \mathrm{~cm}$ in size involving the $\mathrm{S} 4$ nerve roots (Figure 1). The patient was taken to the operating room in conjunction with colorectal and plastic surgery specialists for a low sacral amputation and en bloc resection of the lesion. The patient tolerated the procedure well and was discharged home on postoperative day 1. Pathology was consistent with a chordoma with negative surgical margins. A postoperative MRI demonstrated no residual tumor. Given that there was en bloc resection of the tumor with negative margins, adjuvant radiotherapy was deferred. At his threemonth follow-up, the patient was doing extremely well with resolved pain, a well-healed incision, and no neurological deficits nor bowel or bladder deficits. 


\section{Cureus}

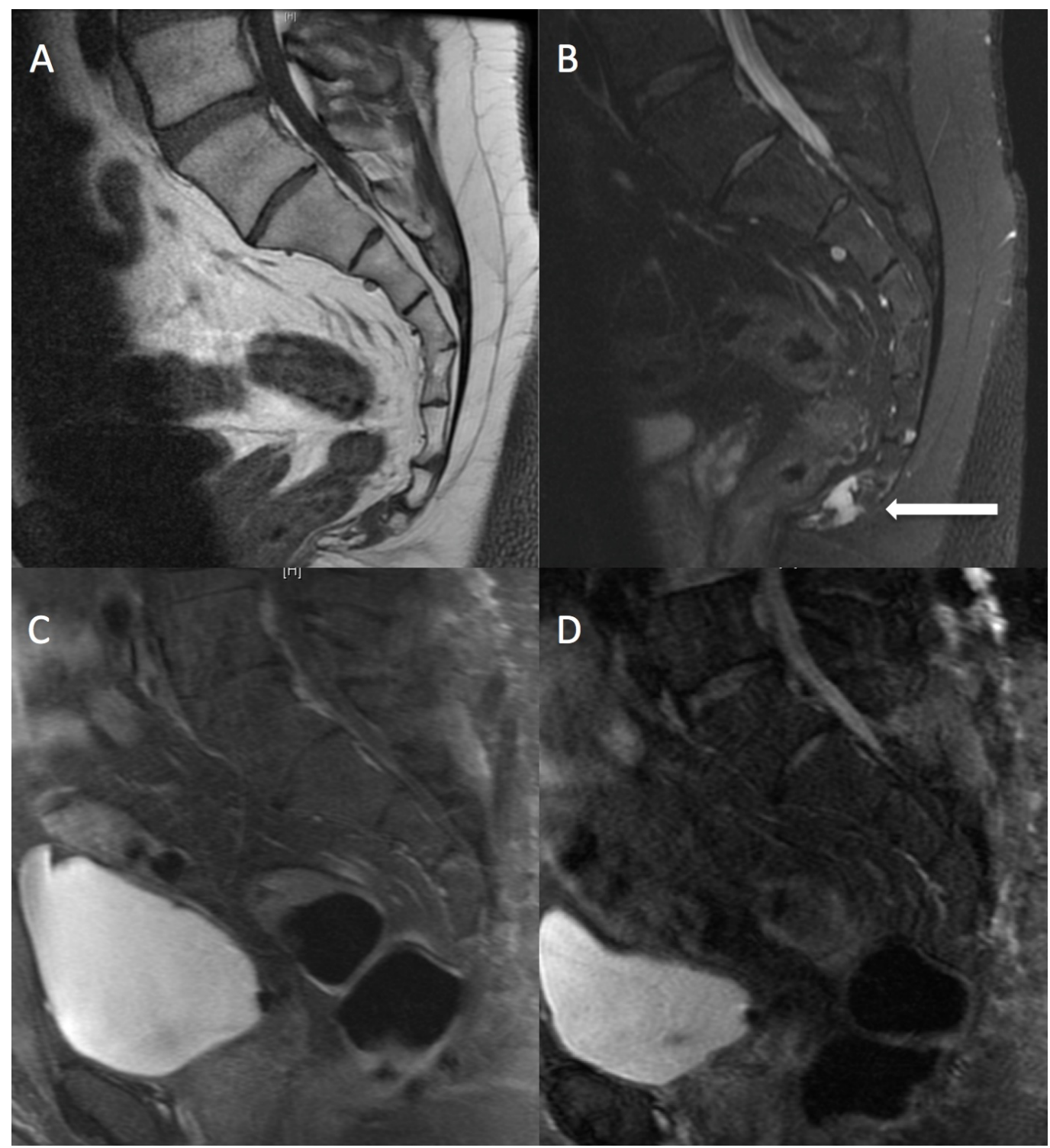

\section{FIGURE 1: Patient 1 - Preoperative and postoperative imaging}

Preoperative MRI (A, B) demonstrates T2 intense well-circumscribed sacrococcygeal mass approximately $3 \times 2 \times 2 \mathrm{~cm}$ in size involving the S4 nerve roots. Postoperative MRI (C, D) shows en bloc total resection of tumor.

\section{Patient 2}

The patient is a 77-year-old previously healthy female who, after a relatively minor fall, was incidentally found to have a 4 × 2 x $4 \mathrm{~cm}$ sacral lesion involving the S2, S3, S4, and S5 nerve roots on CT and MRI. She underwent a CT-guided biopsy demonstrating chordoma. She was asymptomatic at the time of diagnosis and initially elected to pursue close monitoring only. Over the next six months, she began to experience progressive sacral pain. Repeat imaging demonstrated stable tumor size (Figure \#2). Options of en bloc resection and radiosurgery were discussed with the patient. Given her advanced age and invasion of the tumor into the S2 nerve roots, the decision was made to treat the tumor with radiosurgery alone. She was treated with CyberKnife radiosurgery with a dose of $40 \mathrm{~Gy}$ in five sessions (Figure 3). Her follow-up is currently limited, but the patient tolerated the procedure well and was symptom-free six weeks postoperatively. 


\section{Cureus}

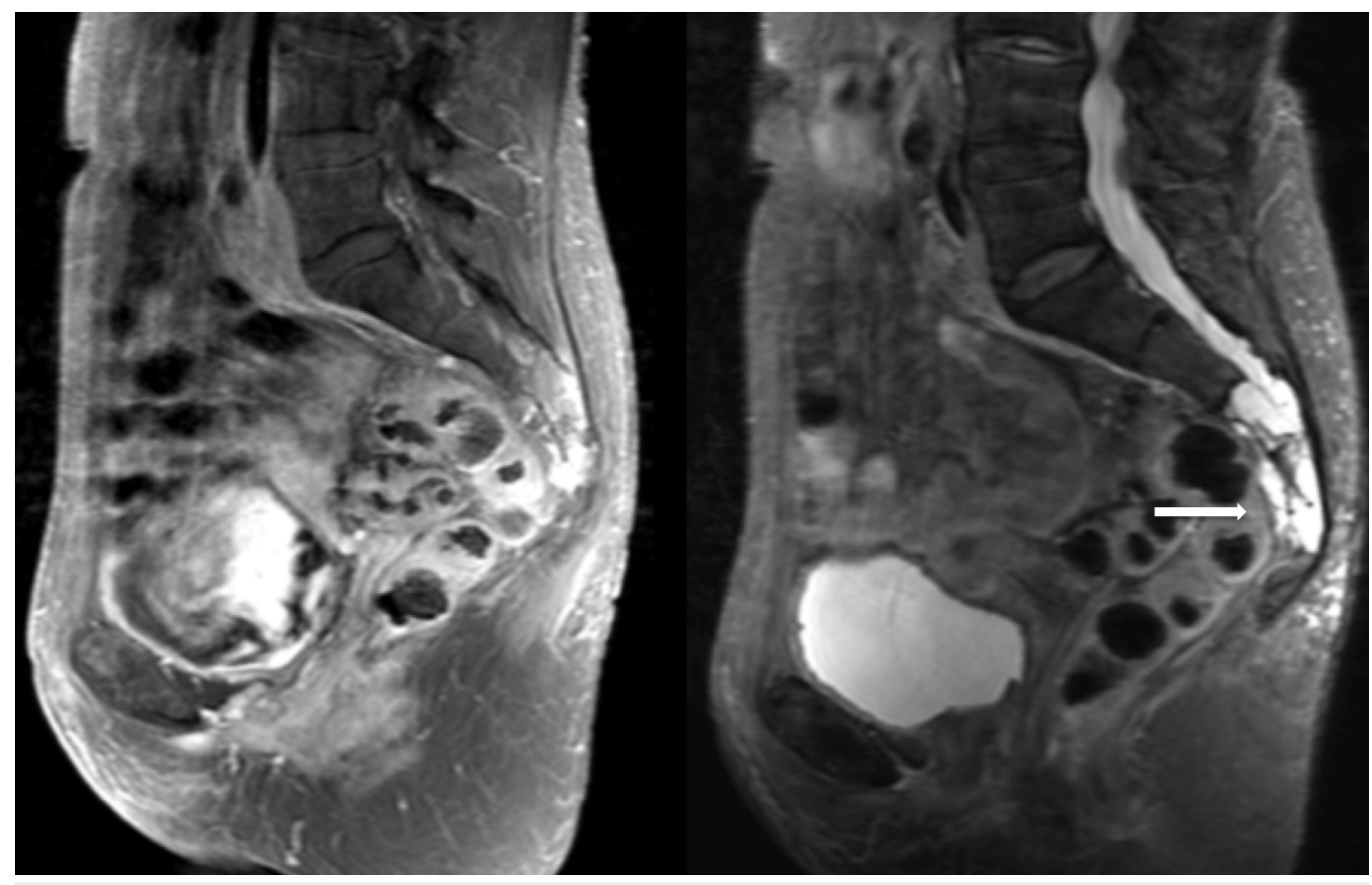

FIGURE 2: Patient 2 - Imaging findings

MRI demonstrates a $4 \times 2 \times 4 \mathrm{~cm}$ sacral lesion involving the S2, S3, S4, and S5 nerve roots.

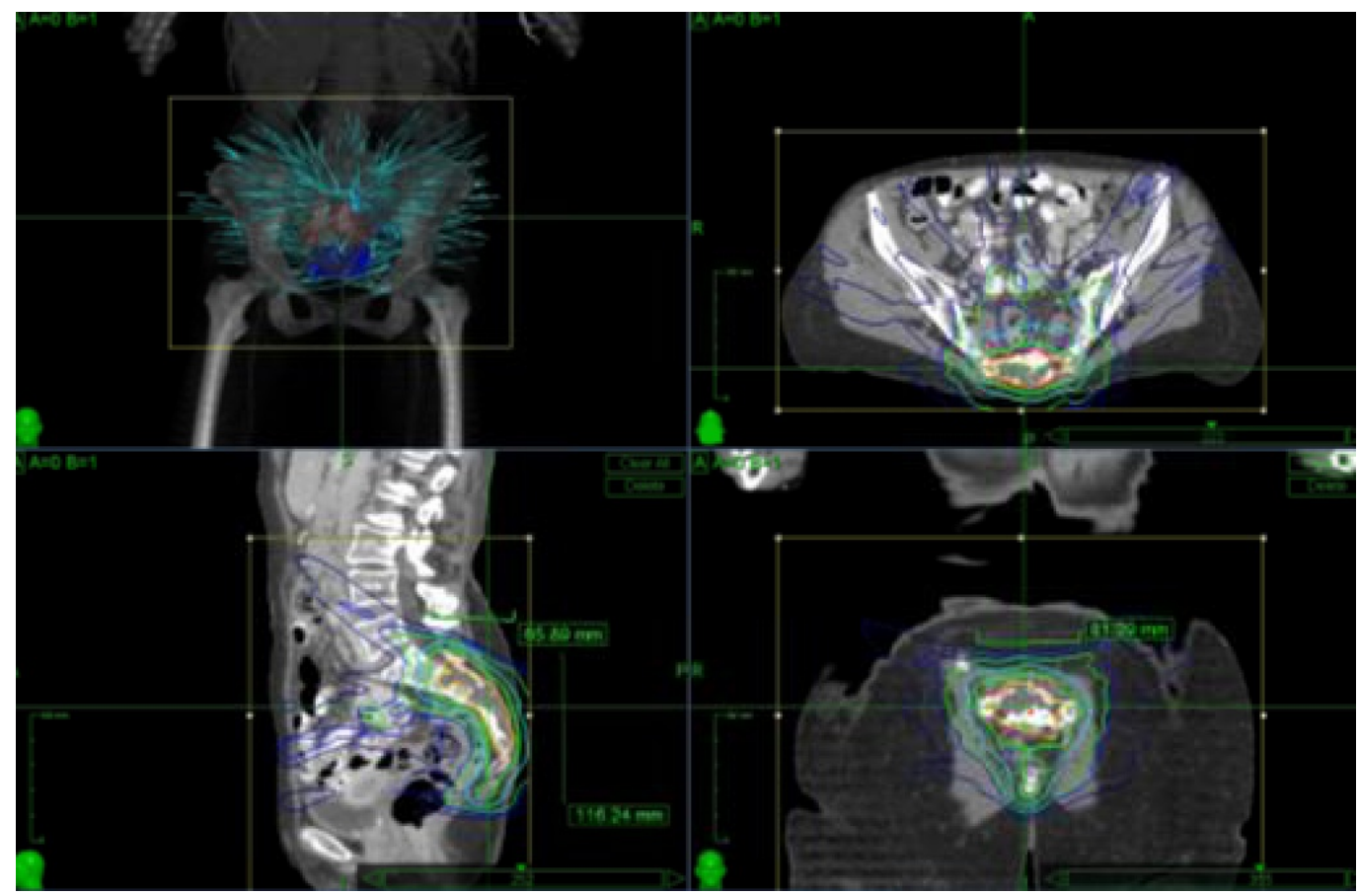

FIGURE 3: Patient 2 - CyberKnife radiosurgery plan

40 Gy was delivered in 5 sessions.

\section{Discussion}




\section{Management strategies}

Sacral chordomas represent a challenging clinical entity due to often large tumor size and advanced disease progression at the time of presentation. Although treatment can require multiple disciplines and incurs a risk of morbidity and decreased quality of life, surgical resection remains the definitive method of preventing local recurrence and minimizing overall mortality [4-5].

Kaiser, et al. first demonstrated the superiority of en bloc resection using a posterior approach in sacrococcygeal chordoma. Complete excision of the tumor without contamination of the surgical wound resulted in a $28 \%$ recurrence rate compared to $64 \%$ with subtotal resection [6]. Subsequent studies have corroborated these findings and expanded on other prognostic indicators, including tumor size $>8 \mathrm{~cm}$, infiltration of the sacroiliac joints and/or adjacent musculature, and gluteus maximus or piriformis invasion [7].

\section{Surgical principles}

The operative approach to sacral chordomas is tailored to lesion size and relationship to the sacrum, sacroiliac joints, and sacral nerve roots. Combined anterior-posterior approaches may be required in some circumstances. Lumbopelvic reconstruction with instrumented fusion is recommended in cases involving the majority of the sacroiliac joint, or when a total or high sacrectomy is performed and can be achieved using the modified Galveston technique [8-9]. For mid- and low-sacral chordomas, due to the preservation of the sacroiliac joint, lumbopelvic reconstruction is not typically required. Disconnection of the anococcygeal ligament and safe dissection of the tumor from the ventral pelvic structures is often aided by collaboration with a colorectal surgeon. Postoperative complications related to pressure-dependent wound breakdown and infection are a major source of morbidity following sacrectomy [10], and therefore, collaboration with plastic surgery for a layered wound closure with or without a flap, is beneficial.

\section{Neurological outcomes}

With the goal of total resection, patients with sacral chordomas can experience postoperative morbidity related to motor, bowel and bladder function. The most significant predictors of postoperative function are preoperative function and level of sacrectomy [11]. The sacrifice of the S2 nerve roots and roots distal to this can risk impaired postoperative urinary and bowel function [12]. Rates for high sacrectomy are near $100 \%$ for moderate to severe postoperative bowel and bladder dysfunction but decrease to $75 \%$ and $12.5 \%$ with mid or lower sacrectomy, respectively. Reported rates of bowel/bladder dysfunction after total sacrectomy involving resection of S1 roots are also close to 100\%. Resection of S1 nerve roots can also increase the incidence of postoperative plantar flexion weakness and requirement of ankle orthosis for ambulation in approximately $40 \%$ of patients [12]. Bilateral resection of sacral nerve roots involving S2-S5 results in 100\% bowel and bladder dysfunction. Bilateral S2 sparing yields $40 \%$ and $25 \%$ preservation of bowel and bladder function, respectively and improves to $100 \%$ and 69\% when preserving S2 and S3 roots. Unilateral nerve root sparing is associated with improved neurological outcomes and recovery with a return of function at approximately six to eight months [13]. Unilateral preservation of S3 carries a $67 \%$ and $60 \%$ chance of intact bowel/bladder function suggesting that a majority of patients can retain an adequate quality of life post-sacrectomy [14].

\section{Radiosurgery}

Chordomas are considered to be poorly responsive to traditional radiation therapy techniques [15]. Development of stereotactic radiosurgery techniques, however, raises the possibility of increased dose application to the tumor with improved outcomes. Several papers have reported 
good outcomes with high dose per fraction regimens as a salvage therapy for patients who could not undergo surgical resection. Five-year local control rates are estimated between 35-60\% while overall survival rate is approximately $74 \%$ [16]. High-dose single-fraction stereotactic radiosurgery has been shown to control local disease progression in up to $95 \%$ of patients at 24 months [17].

The role of adjuvant radiation therapy remains controversial. Several studies have failed to show a benefit of adjuvant therapy when en bloc resection is achieved [18]. One group has reported a trend towards an increase in overall survival after en bloc resection and initial radiotherapy [15]. There has also been a reported increase by approximately 16 months in disease-free survival with adjuvant radiotherapy after both subtotal or radical resection [4]. Proton beam therapy may also represent a promising therapeutic avenue. Fiveyear local control rates on patients with surgery and radiation are reported as $90 \%$ for primary and $57 \%$ for recurrent lesions [19]. Radiotherapy may also delay the time to local recurrence specifically in patients with partial resection [20-22].

\section{Reoperation after recurrence}

When recurrence does occur, it commonly involves the soft tissues around the sacrum, including the piriformis and gluteus maximus muscles. There may be a role for reoperation after recurrence but only with complete resection [23]. These cases are noted to be exceptionally difficult due to scarring and obscured tumor margins.

\section{Conclusions}

Sacral chordoma is a complex clinical entity which often presents in a delayed fashion leading to large tumor size and involvement of critical neural elements in the sacrococcygeal region. For those patients who can tolerate the operation, en bloc resection with a multi-disciplinary team of colorectal and wound specialists is the gold standard for limiting recurrence and maximizing survival. The role of radiotherapy in an adjuvant role or in recurrence remains unclear. For patients who cannot tolerate an operation, radiation may provide a less optimal option for disease control in a limited fashion.

\section{Additional Information \\ Disclosures}

Human subjects: Consent was obtained by all participants in this study. Stanford University Institutional Review Board issued approval. Conflicts of interest: In compliance with the ICMJE uniform disclosure form, all authors declare the following: Payment/services info: All authors have declared that no financial support was received from any organization for the submitted work. Financial relationships: All authors have declared that they have no financial relationships at present or within the previous three years with any organizations that might have an interest in the submitted work. Other relationships: All authors have declared that there are no other relationships or activities that could appear to have influenced the submitted work.

\section{References}

1. Walcott BP, Nahed BV, Mohyeldin A, Coumans JV, Kahle KT, Ferreira MJ: Chordoma: current concepts, management, and future directions. Lancet Oncol. 2012, 13:e69-76. 10.1016/S14702045(11)70337-0

2. Mukherjee D, Chaichana KL, Gokaslan ZL, Aaronson O, Cheng JS, McGirt MJ: Survival of patients with malignant primary osseous spinal neoplasms: results from the Surveillance, Epidemiology, and End Results (SEER) database from 1973 to 2003. J Neurosurg Spine. 2011, 
14:143-50. 10.3171/2010.10.SPINE10189

3. Fourney DR, Gokaslan ZL: Current management of sacral chordoma. Neurosurg Focus. 2003, 15:E9. Accessed: July 12, 2015: http://thejns.org/doi/abs/10.3171/foc.2003.15.2.9. 10.3171/foc.2003.15.2.9

4. York JE, Kaczaraj A, Abi-Said D, Fuller GN, Skibber JM, Janjan NA, Gokaslan ZL: Sacral chordoma: 40-year experience at a major cancer center. Neurosurgery. 1999, 44:74-9. 10.1097/00006123-199901000-00041

5. Varga PP, Szövérfi Z, Fisher CG, Boriani S, Gokaslan ZL, Dekutoski MB, Chou D, Quraishi NA, Reynolds JJ, Luzzati A, Williams R, Fehlings MG, Germscheid NM, Lazary A, Rhines LD: Surgical treatment of sacral chordoma: prognostic variables for local recurrence and overall survival. Eur Spine J. 2015, 24:1092-1101. 10.1007/s00586-014-3728-6

6. Kaiser TE, Pritchard DJ, Unni KK: Clinicopathologic study of sacrococcygeal chordoma . Cancer. 1984, 53:2574-8. 10.1002/1097-0142(19840601)53:11<2574::AIDCNCR2820531136>3.0.CO;2-5

7. Kayani B, Sewell MD, Tan K-A, Hanna SA, Williams R, Pollock R, Skinner J, Briggs TW: Prognostic factors in the operative management of sacral chordomas . World Neurosurg. 2015, June 23:(in press). Accessed: July 12, 2015: http://www.worldneurosurgery.org/article/S18788750(15)00778-0/abstract. 10.1016/j.wneu.2015.06.030

8. Jackson RJ, Gokaslan ZL: Spinal-pelvic fixation in patients with lumbosacral neoplasms . J Neurosurg. 2000, 92:61-70.

9. Gokaslan ZL, Romsdahl MM, Kroll SS, Walsh GL, Gillis TA, Wildrick DM, Leavens ME: Total sacrectomy and Galveston L-rod reconstruction for malignant neoplasms. Technical note. J Neurosurg. 1997, 87:781-7. 10.3171/jns.1997.87.5.0781

10. Dhawale AA, Gjolaj JP, Holmes L Jr, Sands LR, Temple HT, Eismont FJ: Sacrectomy and adjuvant radiotherapy for the treatment of sacral chordomas: a single-center experience over 27 years. Spine. 2014, 39:E353-9. 10.1097/BRS.0000000000000173

11. Moran D, Zadnik PL, Taylor T, Groves ML, Yurter A, Wolinsky JP, Witham TF, Bydon A, Gokaslan ZL, Sciubba DM: Maintenance of bowel, bladder, and motor functions after sacrectomy. Spine J. 2015, 15:222-9. 10.1016/j.spinee.2014.08.445

12. Fourney DR, Rhines LD, Hentschel SJ, Skibber JM, Wolinsky JP, Weber KL, Suki D, Gallia GL, Garonzik I, Gokaslan ZL: En bloc resection of primary sacral tumors: classification of surgical approaches and outcome. J Neurosurg. 2005, 3:111-122. 10.3171/spi.2005.3.2.0111

13. Baratti D, Gronchi A, Pennacchioli E, Lozza L, Colecchia M, Fiore M, Santinami M: Chordoma: natural history and results in 28 patients treated at a single institution. Ann Surg Oncol. 2003, 10:291-296. 10.1245/ASO.2003.06.002

14. Todd LT Jr, Yaszemski MJ, Currier BL, Fuchs B, Kim CW, Sim FH: Bowel and bladder function after major sacral resection. Clin Orthop Relat Res. 2002, 397:36-39.

15. Moojen WA, Vleggeert-Lankamp CL, Krol AD, Dijkstra SP: Long-term results: adjuvant radiotherapy in en bloc resection of sacrococcygeal chordoma is advisable. Spine. 2011, 36:E656-61. 10.1097/BRS.0b013e3181f8d1f3

16. Yamada Y, Laufer I, Cox BW, Lovelock DM, Maki RG, Zatcky JM, Boland PJ, Bilsky MH: Preliminary results of high-dose single-fraction radiotherapy for the management of chordomas of the spine and sacrum. Neurosurgery. 2013, 70:673-80.

10.1227/NEU.0000000000000083

17. Henderson FC, McCool K, Seigle J, Jean W, Harter W, Gagnon GJ: Treatment of chordomas with CyberKnife: Georgetown University experience and treatment recommendations. Neurosurgery. 2009, 64:A44-53. 10.1227/01.NEU.0000341166.09107.47

18. Schwab JH, Healey JH, Rose P, Casas-Ganem J, Boland PJ: The surgical management of sacral chordomas. Spine. 2009, 34:2700-4. 10.1097/BRS.0b013e3181bad11d

19. Fuchs B, Dickey ID, Yaszemski MJ, Inwards CY, Sim FH: Operative management of sacral chordoma. J Bone Joint Surg Am. 2005, 87:2211-6. 10.2106/JBJS.D.02693

20. Park L, Delaney TF, Liebsch NJ, Hornicek FJ, Goldberg S, Mankin H, Rosenberg AE, Rosenthal DI, Suit HD: Sacral chordomas: Impact of high-dose proton/photon-beam radiation therapy combined with or without surgery for primary versus recurrent tumor. Int J Radiat Oncol Biol Phys. 2006, 65:1514-21. 10.1016/j.ijrobp.2006.02.059

21. Cheng EY, Ozerdemoglu RA, Transfeldt EE, Thompson RC Jr: Lumbosacral chordoma. Prognostic factors and treatment. Spine. 1999, 24:1639-45. 10.1097/00007632-19990815000004 


\section{Cureus}

22. Xie C, Whalley N, Adasonla K, Grimer R, Jeys L: Can local recurrence of a sacral chordoma be treated by further surgery?. Bone Joint J. 2015, 97-B:711-5. 10.1302/0301-620X.97B5.35131

23. Gibbs, IC, Chang SD: Radiosurgery and radiotherapy for sacral tumors. Neurosurg Focus. 2003, 15:E8. 10.3171/foc.2003.15.2.8

24. Todd LT Jr, Yaszemski MJ, Currier BL, Fuchs B, Kim CW, Sim FH: Bowel and bladder function after major sacral resection. Clin Orthop Relat Res. 2002, 397:36-39.

25. Gibbs, IC, Chang SD: Radiosurgery and radiotherapy for sacral umors. Neurosurg Focus. 2003, 15:E8. 10.3171/foc.2003.15.2.8 